Dr J O'Sullivan, Drogheda; Dr J P R Rees, Dublin; Dr M Curtin, Limerick.

We acknowledge the help and guidance of the steering committez, and also Dr P Freyne for p zrtech retate scans; Adani Cranny and staff of the endocrinology section of the central biochemistry laboratories of the Federated Dublin Hospitals; and Mrs Sheila Flynn and the screening laboratory staff Fiona McSweeney, D Liddell, and Denise Horgan, of the Children's Hospital biochemistry laboratory. The staff of Pharmacia (Great Britain and Sweden) have been most helpful Finally, our best thanks go to Mrs Anna Power and Miss Maria Brooks for secretarial work.

\section{References}

1 Dussault JH, Coulombe P, Laberge C, Letarte J, Guyda H, Khoury K. Preliminary report on a mass screening for neonatal hypothyroidism. f Pediatr $1979 ; 85: 670-4$.

2 Anonymous. Screening for congenital hypothyroidism. $\mathrm{Br}$ Med $\mathcal{F}$ 1980; $281: 1-2$.
${ }^{3}$ Fisher DA. Status of neonatal hypothyroidism screening: report from Quebec international conference on neonatal thyroid screening. Stockist JR, Nagataki S, eds. In: Proceedings of the eighth international thyroid congress, Sydney, Australia, 1980. Canberra: Australian Academy of Science, 1980:1-7.

4 Hulse JA, Grant DB, Clayton BE, et al. Population screening for congenital hypothyroidism. Br Med $\mathcal{f} 1980 ; 280: 675-8$.

5 Smith P, Morris A. Assessment of a programme to screen the newborn for congenital hypothyroidism. Community Medicine $1979 ; 1: 14-22$.

${ }^{6}$ Cahalane SF. Phenylketonuria: mass screening for newborns in Ireland. Arch Dis Child 1968;43:141-4.

${ }^{7}$ Cahalane SF. Organisation of screening laboratories. In: Bickel $\mathbf{H}_{\text {, }}$ Guthrie R, Hammersen G, eds. Neonatal screening for inborn errors of metabolism. Berlin: Springer, 1980:287-8.

8 Wolter R, Noël P, De Cock M, et al. Neuropsychological study in treated thyroid dysgenesis. Acta Paediatr Scand 1979;277, suppl:41-6.

9 Starfield B, Holtsman NA. A comparison of effectiveness of screening for phenylketonuria in the United States, United Kingdom and Ireland. $N$ Engl f Med 1975;293:118-21.

(Accepted 25 September 1980)

\title{
How long does it take to become fit?
}

\author{
JOHN PEARN
}

\section{Summary and conclusions}

To become fit an individual must generate optimal muscle strength and must develop cardiopulmonary reserve, or stamina. Physical fitness programmes require motivation, a graded series of appropriately designed exercises, and scientific surveillance. Motivation and efficiency in fitness programmes depends on early positive feedback to participants, confirming that stamina and strength are developing.

A practical field experiment was performed to determine the minimum time that healthy young adults require to reach an initial plateau in objective measures of fitness. Fifty male university undergraduates were studied during an annual volunteer military training camp. Thirty had volunteered to take part in the fitness programme; the remaining 20 had initially rejected the offer but underwent the programme as part of their military training and acted as unmotivated controls. All the subjects became fit within 14 days of starting training, with objective improvement in both absolute strength and pulse recovery times.

Non-motivated individuals, training with motivated individuals for 20 minutes each day, can therefore achieve levels of fitness indistinguishable from those of healthy highly motivated subjects. Fitness programmes must be carefully supervised, however, with medical examinations for those about to undergo vigorous exercise.

\section{Introduction}

Current interest in physical fitness programmes is high. To become fit an individual must develop both optimal muscle strength and cardiopulmonary reserve or stamina. The

2 Field Hospital, Brisbane, Australia

JOHN PEARN, MD, lieutenant-colonel, RAAMC generation of, and tests for, these different facets of fitness are quite distinct but complementary. ${ }^{1}$ To achieve these two prerequisites of fitness, an out-of-condition sedentary individual must have (a) motivation, (b) a suitable training and exercise environment, ${ }^{2}$ and $(c)$ an acceptance of some inevitable physical discomfort.

Persistence with a programme of fitness training depends largely on the certainty that success will be possible and on the presence of signs that improvement is occurring rapidly. For all but children and healthy young adults, exercise challenge should be gradual and unobtrusive ${ }^{3}$ and medically supervised. Analysis of motivational factors leading to participation in vigorous physical training has shown that a desire to keep fit and to achieve a subjective feeling of well being is the most important. $^{35}$ It is known, however, that positive attitudes towards physical education are not necessarily correlated with high scores of physical fitness. ${ }^{6}$

In the case of adolescents and young adults, motivation is quickly lost if results are not achieved. "How long does it take to get fit ?" is thus an important question that the doctor is asked whenever he recommends that an individual start a training programme. I report here the results of a study to answer this question in subjects of both high and low initial motivation.

\section{Methods}

Background-This study was undertaken during routine training in an annual army camp (Army Reserve) of 16 days' duration. Test subjects comprised 50 healthy male students aged 18-24 years.

Physical fitness programme-A standard 10-station training circuit ${ }^{7} 8$ was established. Each station consisted of a standard physical task (Harvard step test, "chin-up" horizontal bar, body-press site, etc) Subjects set their own initial task baselines in standard fashion. ${ }^{4}$ The fitness programme then consisted of three sequential circuits of the 10-station course, at maximum speed against a stopwatch. Each individual undertook the training session twice daily for 14 consecutive days, under close supervision. Course times varied from eight to 14 minutes (see fig 1). Unlike other combat conditioning courses, subjects in this study were not involved in other strenuous physical activities during the duration of the tests. Normal warm-ups were 
not undertaken because of the known objective ${ }^{910}$ and subjective ${ }^{11}$ variable influence of this on physical performance.

Subjects-The nature of the study was explained to the 50 university undergraduates, 30 of whom had volunteered to undertake the programme. This highly motivated group formed the test group. The remaining 20 individuals, who had initially rejected the proffered programme, then comprised a control group and undertook the physical training as part of their normal military training. All 50 individuals were completely healthy by rigid and comprehensive Army selection standards. All individuals were medically examined before and during the study, and all (both test subjects and controls) completed the training programme.

Measurement of fitness-The time taken to complete each training circuit, pulse recovery curves (pulse rates at two, five, and 10 minutes), and weight were recorded individually for each session. A modified physical fitness index was developed using individual pulse recovery curves. The standard physical fitness index uses the Harvard step test, with pulse recovery curves sampled at one, two, and four minutes $^{7}$ after cessation of the submaximal effort. The bradycardia which develops with endurance training, even in children, ${ }^{12}$ is the cause of a progressive increase in the physical fitness index. Because of evidence that suggests that indices of physical fitness are more sensitive indicators when used following an "all-out" test rather than a submaximal effort, ${ }^{13}$ a modified index was developed for this study. This used the 8-14 minute maximum effort on the mixed-exercise circuit as the endurance challenge, with sampling of the pulse recovery curve at two, five, and 10 minutes after completion of the circuit. The formula comprised:

$$
\text { modified physical fitness index }=\frac{30000}{\mathrm{P} 2+\mathrm{P} 5+\mathrm{P} 10}
$$

where $\mathrm{P} 2, \mathrm{P} 5$, and $\mathrm{P} 10$ were the minute pulse rates 2,5 , and 10 minutes after completion.

\section{Results}

Sequential improvement in strength and stamina is shown in fig 1 . In these healthy subjects a twice-daily (8-14 minutes) vigorous training session produced significant improvement after six days; after 12 days of continuous training the improvement curve had started to flatten. Poorly motivated individuals performed less well initially, although when training was continued in a group setting they quickly caught up (fig 1). Within three days of the start of the

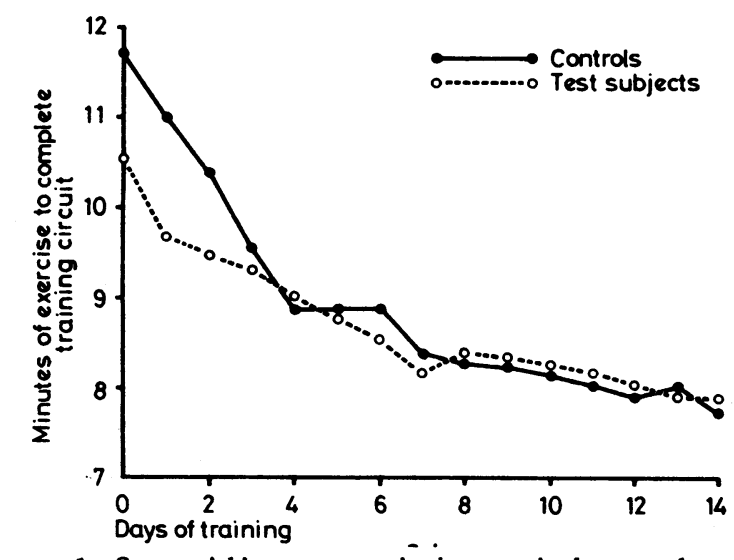

FIG 1-Sequential improvement in time required to complete training circuit in $\mathbf{3 0}$ highly motivated test subjects and 20 controls.

programme, and despite differences between the two groups, rates of improvement and objective times to complete the circuit were indistinguishable $(p>0.05)$. Fig 2 shows that for the 30 highly motivated subjects pulse recovery times had improved significantly after 14 days' continuous training; the modified physical fitness index increased from a mean (for all 50 subjects) of 80 to 97 over this period. Fig 3 shows pulse recovery times in control and test subjects at the end of the 14-day training period. Despite initial differences in motivation, the pulse-recovery curves were indistinguishable. The interpretation of this finding is that six hours of circuit training, spread evenly over
14 days, will achieve a mean increase in physical fitness index of $20 \%$, irrespective of initial enthusiasm and motivation. Retesting of strength performance at the end of the course showed a mean increase of $28 \%$ in the number of repetitions that could be achieved, again with no difference in such improvement between the control and test groups $(\mathrm{p}>0.05)$.

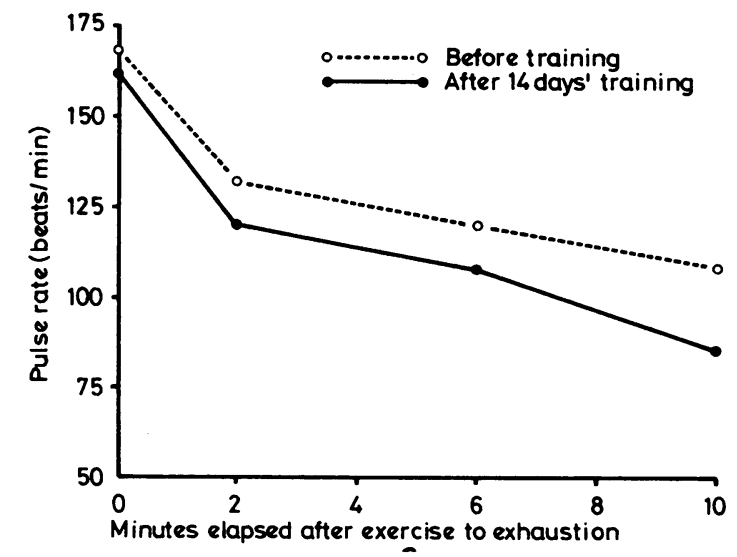

FIG 2-Mean pulse recovery curves (0-10 minutes) after maximum physical effort over 9-14 minutes in 30 healthy and highly motivated test subjects at the start and end of 14-day training programme.

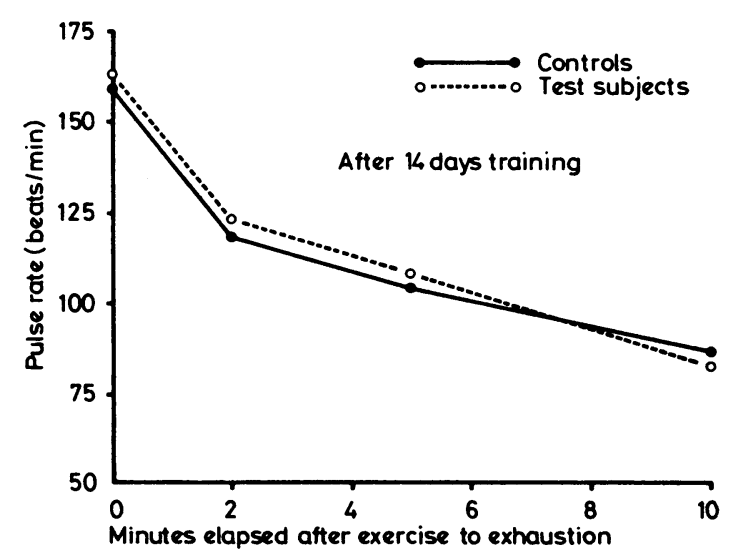

FIG 3-Mean pulse recovery curves after 14 days of training in physical fitness programme in 30 test and 20 control subjects.

\section{Discussion}

An individual's motor performance depends on several invariable factors (height, hand-eye co-ordination, balance, genetically determined and predestined muscle-lever systems) and several factors which can be modified (motivation, static and dynamic power of individual muscle groups, and cardiopulmonary reserve $)$. For development of static and dynamic power both isometric and isotonic ${ }^{14}$ exercises are required. Optimal improvement in cardiopulmonary endurance can be guaranteed only with a formally designed fitness training programme. ${ }^{15}$ Feedback is important both in developing strength in single muscle groups, ${ }^{16}$ and in developing endurance and stamina. For most individuals with suboptimal motivation group support is very important, as this and other studies 217 have shown.

Short-term benefits of successful programmes are well known, ${ }^{35}$ although possible self-selection of participants makes claims for increased longevity difficult to interpret. ${ }^{31819}$ There is both subjective ${ }^{20}$ and experimental ${ }^{21}$ evidence to suggest that chronic physical exertion (within defined limits) provides some cross-adaptation for an individual's ability to cope with stress of novel environments. 
Physical fitness programmes must be carefully supervised, and a preliminary medical examination is essential in cases where vigorous exertion (often to exhaustion) is undertaken by

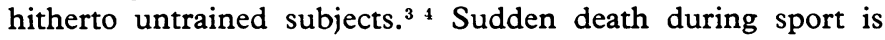
well documented. ${ }^{22} \mathrm{~A}$ family history of early heart attacks and antecedent symptoms of chest pain must be taken seriously.

Provided that such safeguards are observed, this study has shown that a healthy young man will achieve significant improvement in absolute strength $(29-30 \%)$ and in stamina or cardiopulmonary reserve $(15-25 \%)$ within two weeks when training for 20 minutes a day. Prolonged training can improve a subject's physical fitness index from 80 to 120 over several months (Zatopek achieved an index of 172 when tested using a Harvard step test of 20 inches $^{7}$ ); but just as fitness can be achieved quickly, once training stops regression occurs quickly. Five weeks after cessation of an efficient training course, enduranceproduced electrocardiogram changes have already disappeared. ${ }^{13}$

I thank colleagues of the Queensland University Regiment, and the 21 Psychology Unit, Royal Australian Army, for their help, and Brigadier R I Harrison for support.

Requests for reprints should be sent to: Dr John Pearn, Department of Child Health, Royal Children's Hospital, Herston, Brisbane, Australia 4029.

\section{References}

1 Rasch PJ, Wilson ID. The correlation of selected laboratory tests of physical fitness with military endurance. Milit Med $1964 ; 129: 256-8$.

2 Buxaum R, O'Connor R. Fitness trials. $N$ Engl f Med 1977;296:690-1.

3 Bannister R. Sport, physical recreation and the national health. Br Med $\mathscr{f}$ $1972 ; 4: 711-5$

4 Adamson GT. Training methods. Physiotherapy 1972;58:207-10.
${ }^{5}$ Brunner BC. Personality and motivating factors influencing adult participation in vigorous physical activity. Res $Q \mathrm{Am}$ Assoc Health Phys Educ 1969;40:464-9.

${ }^{6}$ Campbell DE. Relationship between scores on the Wear attitude inventory and selected physical fitness scores. Res $Q \mathrm{Am}$ Assoc Health Phys Educ $1969 ; 40: 470-4$

${ }^{7}$ Morgan RE, Adamson GT. Circuit training. 2nd ed. London: G Bell and Sons, $1961: 65-91$

8 Rasch PJ, Otott GE, Brown M, Wilson ID, Norton RJ. Evaluation of a new combat conditioning course. Milit Med 1966;131:130-6.

${ }^{9}$ Martin BJ, Robinson S, Wiegman DL, Aulick LH. Effects of warm-up on metabolic responses to strenuous exercise. Med Sci Sports 1975;7: 146-9.

${ }^{10}$ Malarecki I. Investigation on physiological justification of so-called "warming-up." Acta Physiol Scand 1954;5:543-6.

11 Massey BH, Johnson WR, Kramer GF. Effect of warm-up exercise upon muscular performance using hypnosis to control the psychological variable. Res $O \mathrm{Am}$ Assoc Health Phys Educ 1961 ;32:63-71.

12 Marcano BA, Moss AJ. Spurious heart disease in athletic children. f Pediatr 1968;72:664-8.

13 Fardy PS. Effects of soccer training and detraining upon selected cardiac and metabolic measures. Res $Q$ Am Assoc Health Phys Educ 1969;40: 502-8.

14 Huxley AF. Muscular contraction. F Physiol $1974 ; 243: 1-43$

15 Cumming GR, Goulding D, Baggley G. Failure of school physical education to improve cardiorespiratory fitness. Can Med Assoc $\mathcal{F}$ $1969 ; 101: 69-73$.

16 Abraham WM, Craig AB. Tension decline during isometric contractions without visual cues. Med Sci Sports 1975;7:99-104.

17 Todd FE. Democratic methodology in physical education. Sociometry $1951 ; 14: 203-9$.

18 Bassler TJ. Previous health and longevity of male athletes. Lancet 1972; ii:711-2.

19 Polednak AP. Previous health and longevity of male athletes. Lancet $1972 ; \mathrm{ii}: 711$.

${ }^{20}$ War Office (UK). A guide to the organisation and control of physical training. London HMSO, 1963 (WO Code No 9853), 5.

${ }^{21}$ Tharp GD, Carson WH. Emotionality changes in rats following chronic exercise. Med Sci Sports $1975 ; 7: 123-6$.

22 Opie LH. Sudden death and sport. Lancet $1975 ; \mathrm{i}: 263-6$.

(Accepted 15 October 1980)

\title{
Grey-scale ultrasonography and percutaneous transhepatic cholangiography in biliary tract disease
}

\author{
S R WILD, J G CRUIKSHANK, G M FRASER, W A COPLAND, D C GRIEVE
}

\section{Summary and conclusions}

Fifty-one patients with suspected obstructive jaundice and 14 without jaundice in whom disease of the biliary tract was suspected but infusion cholangiography had been unhelpful were examined by grey-scale ultrasonography and percutaneous transhepatic cholangiography and the findings analysed retrospectively. Grey-scale ultrasonography distinguished between obstructive and hepatocellular jaundice in 35 out of 46 patients $(76 \%)$ and indicated the site of the obstruction in $27(58 \%)$ and the cause of the obstruction in $13(28 \%)$. Percutaneous transhepatic cholangiography distinguished between obstructive and hepatocellular jaundice in 42 of the patients $(91 \%)$ and indicated the site of the obstruction in $42(91 \%)$ and the cause in $29(63 \%)$. In the 14 patients without jaundice percutaneous transhepatic cholangio-

\footnotetext{
Department of Radiodiagnosis, Western General Hospital, Edinburgh EH4 2XU

S R WILD, MB, FRCR, consultant radiologist

J G CRUIKSHANK, FRCP, FRCR, consultant radiologist

G M FRASER, MB, FRCR, consultant radiologist

W A COPLAND, FRCSE, FRCR, consultant radiologist

D C GRIEVE, MB, FRCR, consultant radiologist
}

graphy showed bile-duct stones in one and ampullary stenosis in three.

It is concluded that grey-scale ultrasonography and percutaneous transhepatic cholangiography are complementary examinations and that ultrasonography should always be undertaken first as it is a non-invasive procedure that may provide the surgeon with all the diagnostic information he requires. Percutaneous transhepatic cholangiography should be performed when grey-scale ultrasonography has shown dilated bile ducts but failed to provide adequate diagnostic information. Cholangiography is also required when preoperative percutaneous drainage of the bile duct is contemplated. In those patients in whom grey-scale ultrasonography shows non-dilated ducts endoscopic retrograde cholangiopancreatography is probably the contrast examination of choice.

\section{Introduction}

Percutaneous transhepatic cholangiography is a reliable method of differentiating obstructive from hepatocellular jaundice with an accuracy of between $96 \%$ and $100 \% .^{12}$ In one series the technique detected the cause of the obstruction in $71 \%$ of cases, $^{3}$ and in another was claimed to be $100 \%$ accurate in 